\section{Estereótipos de gênero e leitura multimodal crítica na formação continuada de professores de línguas}

\author{
Gender stereotypes and critical multimodal reading in \\ continuing education of language teachers
}

\section{Roziane Keila Grando (iD) 9}

kekegrando@yahoo.com.br

Universidade Estadual de Campinas - UNICAMP

\section{Resumo}

Com a dinâmica de textos multimodais e a sua presença nas práticas sociais, o ensino de leitura vem demandando investimento na formação crítica do leitor e dos formadores de leitores. Essa formação é possível por intermédio da Pedagogia dos Multiletramentos no ensino de línguas. Assim, optar por um ensino de línguas que esteja ancorado nos multiletramentos abre espaço para a inclusão das questões identitárias e para a divulgação dos direitos humanos na Escola. A partir desse recorte, o objetivo do trabalho é analisar um evento de formação de professores que versou sobre o anúncio audiovisual da cerveja Skol, intitulado "Reposter - Redondo é sair do seu passado", veiculado no ano de 2017. A problematização da discussão recai sobre como a linguagem tem sido usada na condição de suporte para as diferenças de gênero. Inscrita no campo da Linguística Aplicada, a pesquisa caracteriza-se como um estudo de caso, com uma abordagem interpretativista. Os dados obtidos nesse estudo de caso ajudam na compreensão de que é necessário investir na agenda de formação que auxilie no entendimento de que tratar de diversidade cultural também envolve tratar das identidades de gênero.

\section{Palavras-chave}

Leitura crítica; Multiletramentos; Gênero; Anúncio audiovisual.

\section{Abstract}

With the dynamic of multimodal texts and its presence in the social practices, the teaching of reading demands effort in the critical reader's training and the readers formation. That formation is possible through using Multiliteracies Pedagogy in language teaching. Therefore, we chose the language teaching method anchored in Multiliteracies, to open spaces to the inclusion of Identitarian matters and for the promotion of Human Rights at school. In this way the aim of this article is to analyse an event of teacher's continuing training about multiliteracies coming from the audiovisual advertisement of the beer brand Skol, entitled "Reposter- redondo é sair do seu passado", disseminated in 2017. The problematization falls upon how language has been used on the condition of support for the gender differences. Inscribed in the applied linguistics field, the research is characterized like a case study with an interpretative approach. The data in this case study helps understand the necessity of investing in training teachers to understand that, discussing cultural diversity, also involves talking about gender identities.

\section{Keywords}

Critical Reading; Multiliteracies; Gender; Audiovisual.

\section{Linguagem Foco}

Revista do Programa de Pós-Graduação em Linguística Aplicada da UECE

FLUXO DA SUBMISSÃO

Submissão do trabalho: 16/10/2019 Aprovação do trabalho: 05/11/2020 Publicação do trabalho: 22/01/2021

\section{COMO CITAR}

GRANDO, Roziane Keila. Estereótipos de gênero e leitura multimodal crítica na formação continuada de professores de línguas. Revista Linguagem em Foco, v.12, n.3, 2020. p. 321-338. Disponível em: https://revistas.uece.br/index.php/linguagememfoco/article/view/3815. 


\section{Introdução}

A multimodalidade pode ser entendida como uma situação em que significados são criados, distribuídos, recebidos e interpretados por meio da combinação de diferentes modos semióticos, os quais são compreendidos como recursos culturalmente disponíveis para a criação de sentido, ou ainda, tecnologias para representação de significados (KRESS; JEWITT, 2003). Nesse sentido, tratar de multimodalidade é versar sobre como os sentidos são construídos socialmente.

O fato de vivermos e contextos socioculturais cada vez mais diversos não somente em termos de linguagens, mas também em termos de identidades sociais fez surgir o manifesto "A pedagogy of multiliteracies: designing social futures", originado do encontro de setembro de 1994, em que se reuniram educadores de diferentes áreas do conhecimento e também de diferentes experiências e culturas, com o objetivo de se discutir e repensar o futuro dos estudos do Letramento, considerando a diversidade cultural e as mudanças tecnológicas associadas à forma como se constrói sentidos socialmente a partir da relação com as TICs (Tecnologias de informação e comunicação).

Dessa reunião, surgiu o grupo então denominado The New London Group (Grupo de Nova Londres) o qual teve como pauta de discussão sobre o que ensinar (aumento, integração e multiplicidade na forma de relacionar os significados em um texto) e como ensinar atualmente (abordagem do ensino considerando a diversidade e pluralidade de contextos e perfil de alunos).

Relacionado ao como, sugere-se um estudo que verse sobre as diferenças linguísticas e culturais da sociedade cada vez mais globalizada. Segundo os pesquisadores do grupo,

[...] lidar com as diferenças linguísticas e culturais tornou-se central para a pragmática de nossas vidas profissionais, cívicas e privadas. Uma efetiva cidadania e um trabalho produtivo requer que possamos interagir efetivamente usando múltiplas linguagens, em múltiplos ingleses e padrões de comunicação que cruzam fronteiras nacionais, culturais e comunitárias (CAZDEN et al, 1996, p. 64).

Se o Manifesto problematiza "os estudos semióticos dos textos, envolvendo diferentes formas de produção, veiculação e consumo, expandindo, assim, o conhecimento sobre letramentos" (PINHEIRO, 2016, p.1), é justamente isso que me interessa, pois, junto ao grupo de Nova Londres, destacou-se a perspectiva da Semiótica Social, a qual proporciona uma metalinguagem, utilizando-se da 
descrição de recursos semióticos, permitindo entender o que se diz e faz com imagens (e outros meios de comunicação visual), bem como permite interpretar as coisas que as pessoas dizem e fazem com imagens (JEWITT; OYAMA, 2004).

Tendo em vista a proposta da pedagogia dos multiletramentos, pretendo mostrar parte dos resultados de um estudo de caso, realizado por meio da estratégia de geração de dados com um grupo focal, ocorrido no ano de 2017, em um evento de formação continuada de professores de Línguas sobre leitura multimodal crítica.

Em específico, farei a análise de um evento de formação de professores que versou sobre o anúncio audiovisual da cerveja Skol, intitulado "Reposter - Redondo é sair do seu passado", veiculado no ano de 2017. Essa situação de formação continuada permitiu a problematização sobre como a linguagem tem sido usada na condição de suporte para as diferenças de gênero.

Para tanto, em um primeiro momento, recorro à discussão de conceitos sobre as identidades sociais ligados ao conceito de representação. Na sequência, discuto o funcionamento da multimodalidade e sua relação com as estratégias de criação publicitária. Por fim, apresento e analiso o anúncio por meio da Gramática do Design visual (KRESS, VAN LEEUWEN, 2006) apoiando-me em autores dos estudos culturais e de gênero, tais como Silva (2014), Butler (2016) e Nicholson (1990) entre outros.

\section{Educar para a diferença e a compreensão dos estereótipos de gênero}

Tratar das pessoas e como elas significam as coisas pode ser visto pelo prisma do estudo das identidades, estando ligado "a sistemas de representação. A identidade tem estreitas conexões com relações de poder" (SILVA, 2014, p. 97). É por isso que o modo como a linguagem é usada faz com que as identidades sejam construídas e elaboradas. Assim, o valor das palavras no discurso pedagógico não pode "ser menosprezado porque elas acionam processos de identificação e estes, muitas vezes, provocam sofrimento quando a identidade traz em si um estigma" (CAVALCANTI; MAHER, 2009, p. 18).

Silva (2014) tem o mesmo posicionamento de Cavalcanti e Maher (2009) e defende que o outro e a diferença não podem ser deixados de lado; devem, assim, ser considerados como matéria de preocupação pedagógica e curricular. Para o autor, é preciso uma estratégia curricular e pedagógica que leve em conta as contribuições da teoria cultural, olhando-as como uma questão política, o que 
possibilita questionar os mecanismos e as instituições que fixam as pessoas de forma compartimentada nas identidades culturais.

Além do exame da própria cultura, Maher (2007, p. 267) sugere ações educativas que possam ser consideradas para o que chama de "educação do entorno". A primeira consiste em "aprender a aceitar o caráter mutável do outro"; a segunda está relacionada a necessidade de aprender a "destotalizar o outro" (sem eleger modelos de padrões culturais).

Sendo a diversidade um dado da natureza, ou da cultura, "a multiplicidade é um movimento. A diversidade reafirma o idêntico. A multiplicidade estimula a diferença que se recusa a se fundir com o idêntico" (SILVA, 2014, p. 101). A diversidade cultural no fazer pedagógico não pode ser ponto de partida, mas de chegada, em um processo de diferenciação. Assim sendo, a política pedagógica e curricular precisa sair das declarações de consentimento e colocar a diferença no centro da teoria, não permitindo que o reconhecimento e a celebração da identidade continuem somente acontecendo, mas seja possível "questioná-las" (SILVA, 2014, p. 98). Dessa forma, ajudando a "favorecer, enfim, toda experimentação que torne difícil o retorno do eu e do nós ao idêntico". (SILVA, 2014, p. 98)

Quando falo de questionamento, recordo das situações, em sociedades, como a nossa, brasileira, da celebração do "Dia Internacional da Mulher". Não se trata de simplesmente "comemorar" a data nas escolas, oferecendo flores às muIheres, por exemplo, como se elas fossem somente dignas de celebração. Esse tipo de abordagem contribui para que os direitos e diferenças, que acontecem com as identidades femininas, continuem no anonimato. As escolas precisam problematizar essa discussão, colocar em pauta e, para isso, é preciso formação, para que possam 'colocar as diferenças no centro da teoria'.

Para tanto, é preciso também voltar o olhar para as práticas linguísticas, as quais se transformam continuamente nas suas comunidades, e são resultados de muitas situações que "[...] entram em jogo por meio de seus múltiplos membros" (ECKERT; MC CONNELL-GINET, 2010, p. 106). Por isso, falar de significação sem considerar as pessoas que as significam e as práticas das comunidades nas quais as pessoas dão sentido às suas palavras, mostra uma visão limitada sobre a diferença. (ECKERT; MC CONNELL-GINET, 2010).

Essas diferenciações acontecem nas comunidades de prática, vistas como um conjunto de ações "e interações observáveis que realizam o trabalho de produzir, reproduzir e resistir à organização de poder na sociedade e nos discursos sociais sobre gênero, idade, raça etc." (ECKERT; MC CONNELL-GINET, 2010, p. 105) 
Costuma-se falar em 'comunidades de prática' que envolvem religião, trabalho, contextos virtuais, esquecendo-se de que a escola acaba também sendo esse espaço em que as relações sociais são heterogêneas, plurais, mas onde, muitas vezes, os discursos que não se alinham ao comportamento hegemônico são excluídos e apagados. Nesse sentido, é preciso educar para a diferença. Segundo Silva (2014), a questão da identidade, da diferença e do outro ser 'um problema social' é, ao mesmo tempo, um problema pedagógico e curricular. Social porque, "em um mundo heterogêneo, o encontro com o outro, com o estranho e o diferente, é inevitável". (SILVA, 2014, p. 97).

Woodward (2014) mostra que a representação funciona simbolicamente para classificar o mundo e nossas relações no seu interior. A identidade passa por duas caracterizações. A primeira é que a identidade é sempre marcada pela diferença. A segunda, de que é marcada por meio de símbolos. Com base em Michel Ignatieff (1994), a autora afirma que a identidade é relacional e que a diferença é estabelecida por uma marcação simbólica relativa às outras identidades. Por isso, a discussão central sobre identidade recai na tensão entre o essencialismo e o não essencialismo. Assim, penso que, no ato de essencialização, a estereotipia pode estar presente.

Espinosa (1993, p. 3) entende o estereótipo como "um mapa cognitivo que simplifica uma realidade pouco conhecida para fazê-la compreensível e cambiável". Para o autor, os estereótipos formam uma parte do componente cultural e são fundamentais para o processo de ensino e aprendizagem de língua. Segundo Guerra (2002), o estereótipo se instala quando as pessoas atribuem significado a algo no mundo sem antes ter um contato real com este 'algo', a interpretação, associada à cultura, determina a noção interna sobre o mundo externo. Quando uma pessoa conhece outra, são ativados interesses, preconceitos, estereótipos, valores, atitudes referentes àquela pessoa, levando à conceitualização harmônica de suas características (relacionadas ao comportamento), bem como à bagagem psicológica que funciona como um 'filtro do estímulo', antes de que se torne um conceito na prática da percepção.

Para Gee (2008), o conflito ocorre ao se combinar: a 'linguagem que usamos', a 'atividade que se faz' e a 'pessoa que somos' no momento em que estamos utilizando um Discurso (com D maiúsculo). Os discursos (com d minúsculo) caracterizam-se pelas escolhas linguísticas compreensíveis, utilizadas para diferentes finalidades (relatos, conversas, trabalhos acadêmicos, afazeres em geral), o

1 No original: "un mapa cognitivo que simplifica una realidad poco conocida para hacerla manejable y comprensible". 
que os diferencia dos discursos que fazem parte de um Discurso.

\section{A Multimodalidade e a criação de um anúncio audiovisual}

Cada vez mais, nos desenvolvimentos tecnológicos, nota-se a linguagem audiovisual em aplicativos webs, baseados no modo verbal oralizado, agregado ao potencial genérico da imagem (fixa e em movimento). Assim, "a imagem vem tomando mais e mais o lugar da escrita no centro do estágio comunicacional. As telas da paisagem contemporânea vêm ganhando espaço no lugar da cultura do impresso" (DOMINGO; JEWITT; KRESS, 2014, p. 2).

Os autores alertam para uma consequência desse espaço que a imagem vem ganhando, que consiste no problema de se analisar a escrita de forma isolada, em contextos multimodais nos quais ela está inscrita. Por isso, o entendimento da função da escrita e o que se quer alcançar com ela sinaliza para uma complexidade quando vista como parte da composição multimodal, de modo que se tornou uma pré-condição, para entender a escrita em contextos online, observar como as tecnologias moldam a linguagem verbal escrita e os outros modos (DOMINGO; JEWITT; KRESS, 2014).

Daley (2010) alerta para uma visão de letramento que partilhe da aprendizagem da leitura e da escrita da linguagem multimidiática da tela. Para a autora, a linguagem multimídia requer atenção sob o aspecto do design, da navegação e dos recursos de interface. Esse aspecto pode ser compreendido se nos ancorarmos na Gramática do Design visual (GDV). Os autores da GDV, Kress e Van Leeuwen (2006), compreendem as imagens como um conjunto de signos internamente regulados, socialmente compartilhados e utilizados para podermos representar e produzir significados.

Neste livro "Reading images: the grammar of visual design", os autores elencam três metafunções de organização do texto visual: metafunção ideacional, metafunção interpessoal e metafunção textual ${ }^{2}$. Os autores postulam que tais metafunções agem de maneira integrada nas imagens, mas que, para compreendê-las, é necessário descrevê-las separadamente.

A metafunção ideacional consiste na descrição de que as imagens comportam o significado de maneira representacional quando exibem aspectos do mundo, tal como é experienciado pelas pessoas. Essa metafunção é construída em torno do falante. Ele incorpora e organiza na língua suas vivências e experiên-

2 As quais derivaram das metafunções pressupostas na Linguística Sistêmico Funcional-representacional, interacional e composicional (HALLIDAY,1994). 
cias do mundo real. São dois os processos que caracterizam esse primeiro princípio: o Processo Narrativo e o Processo conceitual.

A metafunção interpessoal: essa metafunção pode ser observada por meio de três dimensões que projetam as relações entre o produtor, o espectador (leitor) e o participante representado. A primeira dimensão acontece entre participantes representados na imagem; a segunda é a que se dá entre o leitor e o participante representado; a última é a relação estabelecida entre produtor da imagem e o seu leitor (KRESS; VAN LEEUWEN, 2006).

Na Metafunção textual/composicional, as imagens podem ser capazes de formar textos, ou seja, um conjunto de signos que são internamente coerentes e, ao mesmo tempo, coerentes com o contexto produzido (KRESS, VAN LEEUWEN, 2006). Os autores advogam que a essa metafunção estão ligadas as formas pelas quais os elementos interacionais e representacionais são organizados e relacionados com a imagem.

No entanto, entender das metafunções não é suficiente, é necessário compreender como que as habilidades publicitárias sintonizam os registros visuais e verbais "[...] transformando-o num só discurso persuasivo, apto a obter decisões favoráveis em relação ao objeto da mensagem." (MARTINS, J., 2011, p. 155). Para isso, Martins (2011) mostra que são utilizados recursos motivadores dos anúncios, os quais são conduzidos por meio de aspectos argumentativos que norteiam os textos para sensibilizar o público-alvo e traduzir a informação para ele. Martins, J. (2011, p. 158-162) classifica os anúncios, por princípios argumentativos, conforme as seguintes características:

a) Anúncio do onirismo: (termo que alude a uma fantasia, sonho). Nesse tipo de anúncio, é feita a projeção não só da satisfação pessoal, mas também cria a necessidade psicológica de autoafirmação, de economia, de poder gastar. Nesse caso, "o simbólico, o imaginário é consumido no discurso publicitário, o material é consumido no objeto" (p. 158) Expressões como: "compre a sua maneira" ... "ao seu gosto", são comuns.

b) Anúncio de positividade: Esse tipo de anúncio promove o prazer por meio do discurso positivo, exalta a alegria, a moda, os carros... Mostra o "consumo do prazer pela satisfação das necessidades", faz esquecer a realidade da vida. (p. 159): "seu êxito está aqui", "visite-nos".

c) Anúncio de novidade: Procura pela inovação permanente de paradigmas estéticos. "Os objetos de consumo têm que se transmutar continuamente 
para não serem abandonados". A competição força a renovação e a atualização do discurso publicitário e a sua modernização (p. 159). Exemplo: Expressões como: "com ele tudo pesa nada"

d) Anúncio de sedução: O anúncio é apresentado com máscara sedutora, com maquiagem de cores, de belas palavras e de músicas encantadoras. O caminho utilizado é "o da motivação e do clima propício a despertar emoções". Ex. "a magia do sabor está em..." (p. 160-161)

e) Anúncio de hedonismo: A mensagem é para todos, diante do produto, buscando igualdade. Torna o consumidor o indivíduo único, isto é, o discurso é individualizado, de maneira que o espectador pense que é 'para ele' que o anunciador destina seu argumento. "[...] o hedonismo adquire um valor essencial para o homem pós-moderno que se sente livre de escolher e aceitar seu bem-estar em todas as situações e vida e de buscar todo o prazer que a civilização moderna Ihe oferece" (p. 161) Ex. "só aquele que tem bom gosto compra..."

f) Anúncio de narcisismo: Temas que são voltados para a preocupação com o corpo, saúde. Predominância à cultura do corpo, em conservá-lo jovem, sadio. É a que opera milagres. Além disso, há o apelo psicológico, em que se explora a 'cura de traumas', do estresse, angústias na divulgação de consultórios, terapias etc. Ex. "sua pele merece..." (p. 162)

Esses princípios são interessantes para verificar, a partir dos dados gerados, se as professoras em formação continuada conseguem percebê-los enquanto recursos de motivação. O reconhecimento disso pode fazer parte daquilo que envolva uma leitura crítica de um anúncio audiovisual.

Tiago Barreto (2004) discute o impacto que a propaganda pode causar. Consiste em planejar o roteiro de maneira que, o produto, marca ou serviço a ser anunciado, seja lembrado pelo consumidor. São duas as maneiras de provocar o impacto: uma é pelo formato e a outra, pela história.

a) pelo formato: trabalha alguns elementos da estrutura do roteiro de forma criativa, tais como cenas, lettering (formato de palavras), packshot (continuação da história, não só a conclusão) diálogos, locução, trilha e ambientação. (BARRETO, T. 2004, p. 61)

b) pela história: Tudo que foge do esperado, provoca impacto, a surpresa é guardada para o momento certo da narrativa. (BARRETO, T. 2004, p. 62). 


\section{O dispositivo de evocação e o grupo focal: geração dos dados no estudo de caso}

Esta pesquisa define-se como interpretativista, de natureza qualitativa. Consiste em um estudo de caso com observação participante da pesquisadora, dada minha preocupação em manter, na geração de dados, um olhar culturalmente sensível (ERICKSON, 1989) a partir de um contexto específico de formação continuada de professores de línguas.

Em uma ação de grupo focal, trechos de filmes, perguntas, fotografias e outros elementos podem funcionar como gatilhos para a discussão. Lankshear e Knobel (2008) sugerem que estes são 'dispositivos de evocação'. São estratégias para suscitar posicionamentos dos sujeitos da pesquisa acerca de um determinado tema.

Nesta pesquisa, optei por utilizar como dispositivos de evocação um anúncio audiovisual ${ }^{3}$ que possibilita uma discussão acerca da estereotipia do feminino e masculino, Skol reposter.

A escolha pelo Grupo focal deu-se, com base em Bauer e Gaskell (2008, p. 21) os quais recomendam que, nas pesquisas sociais, o interesse esteja na "maneira como as pessoas espontaneamente se expressam e falam sobre o que é importante para elas e como elas pensam sobre suas ações e as dos outros". Com os dados que foram gerados e posteriormente registrados, é possível visualizar e identificar a forma como a realidade social sobre os estereótipos de gênero é representada por esse grupo seleto de professoras (BAUER; GASKELL, 2008).

O grupo focal teve duração de 1h30, com o objetivo de obter subsídios para que eu pudesse investigar a relação e a percepção das professoras em formação sobre os estereótipos de gênero na propaganda em questão.

\begin{tabular}{|c|c|c|}
\hline \multicolumn{3}{|c|}{ Quadro 1 - Descrição geral do anúncio audiovisual } \\
\hline & DESCRIÇÃO DO AUDIOVISUAL & \\
\hline Título do Anúncio/ano & $\begin{array}{c}\text { Estereotipia } \\
\text { no/pelo modo(s) }\end{array}$ & Resumo \\
\hline $\begin{array}{l}\text { Skol Reposter (Skol, } \\
\text { lançada em 2017) }\end{array}$ & $\begin{array}{l}\text { Busca uma desconstrução do corpo } \\
\text { feminino como objeto, mas, utiliza- } \\
\text { se, pelo modo visual, de imagens } \\
\text { que recordam a estereotipia, mesmo } \\
\text { que sutilmente. }\end{array}$ & $\begin{array}{l}\text { A equipe convida ilustradoras para } \\
\text { (re)fazerem os pôsteres antigos da } \\
\text { marca. Neles (pôsteres antigos), os } \\
\text { corpos das mulheres aparecem de } \\
\text { maneira objetificada. } \\
\text { Faz-se uso dos anúncios antigos } \\
\text { para mostrar o antes e o depois, } \\
\text { afirmando-se que a objetificação } \\
\text { feminina não representa mais a } \\
\text { marca. }\end{array}$ \\
\hline
\end{tabular}

Fonte: elaborado pela autora. 


\section{4. $O$ grupo de professoras lendo o anúncio audiovisual}

Do grupo focal realizado, participaram 3 professoras de línguas, sendo uma professora de língua portuguesa, uma de língua inglesa e outra de língua espanhola, todas professoras com experiência no Ensino Fundamental e Médio. Opto, ao apresentar os dados, por utilizar pseudônimos Carolina, em homenagem à escritora brasileira Carolina Maria de Jesus, Frida, em homenagem à artista Frida Kahlo e, Marie, para rememorar a cientista Marie Curie. O Quadro (2) descreve o perfil e tempo de atuação das participantes de pesquisa.

\section{Quadro - 2: Perfil de formação e atuação das participantes}

\begin{tabular}{|c|c|c|}
\hline Participante/cursista & Formação & $\begin{array}{c}\text { Tempo de } \\
\text { atuação como } \\
\text { docente }^{4}\end{array}$ \\
\hline Marie & $\begin{array}{l}\text { Graduada em Letras Inglês } \\
\text { Especialista Literatura e } \\
\text { Contemporaneidade } \\
\text { Mestre em Estudos da Linguagem }\end{array}$ & $\begin{array}{l}12 \text { anos } \\
\text { E.M e E.F } \\
2 \text { anos E.S }\end{array}$ \\
\hline Carolina & $\begin{array}{c}\text { Graduada em Letras Português } \\
\text { Especialista em Ensino de Língua } \\
\text { Portuguesa }\end{array}$ & $\begin{array}{l}15 \text { anos } \\
\text { E. } \mathrm{M} \text { e E.F }\end{array}$ \\
\hline Frida & $\begin{array}{l}\text { Graduada em Letras Espanhol } \\
\text { Especialista em Ensino de Literatura }\end{array}$ & $\begin{array}{l}9 \text { anos } \\
\text { E.M e E.F } \\
4 \text { anos E.S }\end{array}$ \\
\hline
\end{tabular}

Fonte: elaborado pela autora.

Como pode ser percebido, Carolina é quem tem mais tempo de atuação no Ensino básico, seguido de Marie e Frida, respectivamente. Carolina é professora de português, Marie de inglês e Frida de espanhol. Com exceção de Carolina, as demais já atuaram também no Ensino superior. Fiz a escolha das participantes pelo tempo de atuação e formação, considerando também a possibilidade de obter uma amostra com profissionais de idiomas diferentes.

Quando fiz um grupo focal, elegi como dispositivo de evocação o anúncio da Skol reposter, para observar de que maneira as participantes do Grupo focal agiriam, já que tem um discurso que reposiciona a marca da Skol, ao optar pelo politicamente correto. $\bigcirc$ que me chamou a atenção porque foi uma das primeiras coisas que a participante Carolina comentou (linhas 1,2 e 3 - excerto 1).

4 Para E.F, leia-se: Ensino Fundamental; E.M para Ensino Médio e E.S para Ensino Superior. 


\begin{tabular}{rr|}
\hline 1 & Carolina: Achei ousada. Bem legal colocar as mulheres, né .... se colocando \\
2 & como gostariam de ser representadas nas propagandas, não objetificadas, mas \\
3 & como consumidoras de cerveja... o que eu percebi, assim, que mais me chamou \\
4 & atenção nessa propaganda, foram os comentários na propaganda do YouTube, \\
5 & muitos comentários machistas, muita gente criticando, alguns homens até \\
6 & comentando de boicotar a marca por causa desse comportamento, que eu achei \\
7 & lamentável, né, porque achei bem válido a marca fazer essa propaganda... \\
Excerto 7 - Trecho transcrito de gravação do grupo focal (01/07/2017)
\end{tabular}

Uma marca pode buscar um novo posicionamento no mercado tanto pelo produto, quanto pelo trabalho de divulgação. Como pode-se verificar, a Skol optou pela segunda opção. No caso da comunicação, Martins (2011) menciona alguns recursos motivadores de anúncios, os quais são argumentos que norteiam os textos para sensibilizar o público-alvo. É possível verificar que esse anúncio da Skol foi orientado para o argumento que funcione como Anúncio de novidade, já que os objetos de consumo têm que mudar continuamente, buscando uma renovação e atualização do discurso da Skol, a equipe de produção procura atingir um público que, até pouco tempo, "não" se considerava consumidor: o feminino.

Conforme Tiago Barreto (2004), nos estilos de realização de um filme audiovisual, quando o produto é apresentado durante o anúncio, mas sem nenhuma característica sua ser demonstrada, o estilo é orientado para o produto. Em nenhum momento, as participantes representadas (PR) no anúncio falam das qualidades da cerveja Skol. Pela metafunção textual, percebemos que o produto aparece nos cartazes, na escolha do layout, na moldura, pela paleta de cores, como o amarelo, ou os tons rosados presentes na logo. Como pode ser observado nos frames abaixo, figura (1).

Figura 1- Metafunção textual: as cores que remetem ao produto

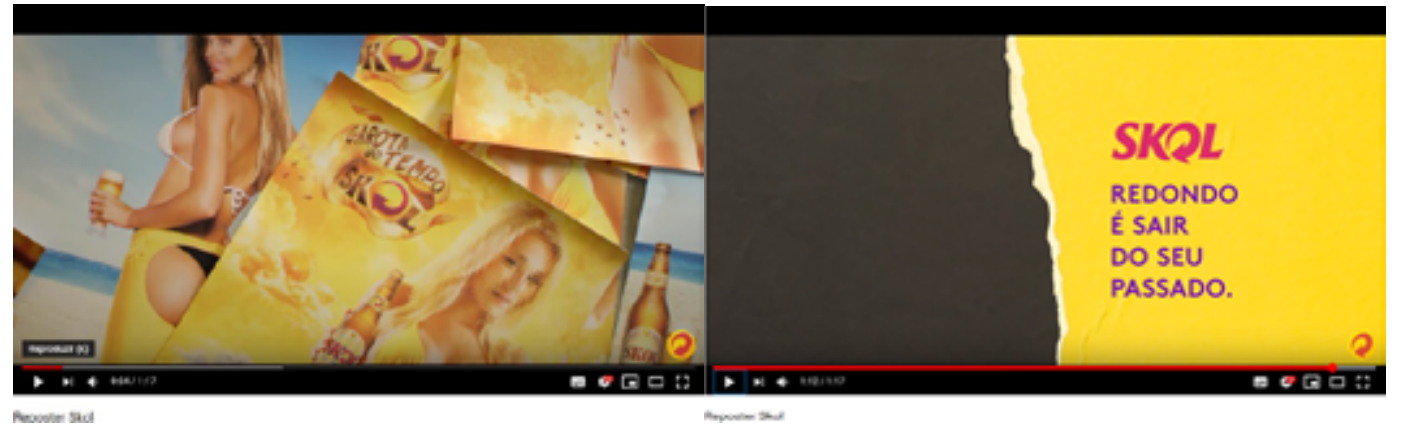

Fonte: https://www.youtube.com/watch?v=tuaP-7P4w2w

Com a metafunção textual, também, pode-se verificar que a cor rosa está em todo o anúncio. Primeiramente, ocupa posição central na imagem, estando presente pela cor do cabelo que a desenhista está pintando no primeiro cartaz 
(frame 1 - figura- 2), e se estende aos demais cartazes, em que as desenhistas optam por utilizá-la para preencher a paisagem, enquanto informação complementar, por aparecer às margens da figura (frame 2 e 3- figura 2). (KRESS; VAN LEEUWEN, 2006).

Figura 2 - O valor da informação no anúncio da skol reposter

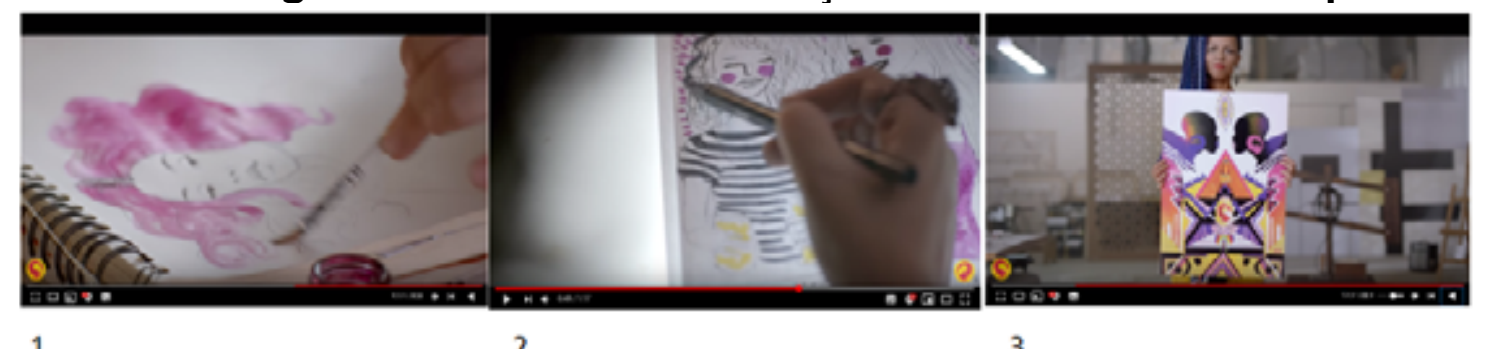

1

2

3

Fonte: https://www.youtube.com/watch?v=tuaP-7P4w2w

Carolina achou válida a proposta que a marca fez em tirar a mulher como sendo representada de forma objetificada, e optar pela sugestão das ilustradoras performarem como as mulheres poderiam ser apresentadas. Além do anúncio, ela fala dos comentários que os usuários da rede fizeram sobre o audiovisual, buscando entender o entorno e de que maneira essa propaganda impactou o público. Essa leitura feita por Carolina, ainda que marcada por uma visão grafocêntrica, porque ela se atém à significação expressa no modo verbal, aponta para o trabalho de leitura e contextualização necessário para a compreensão do texto. O fato de Carolina lamentar os comentários, demonstra que o trabalho com a diferença de gêneros depende do "engajamento mútuo dos agentes humanos em uma ampla gama de atividades que cria, sustenta, desafia e, por vezes, muda a sociedade e suas instituições" (ECKERT; MC CONNELL- GINET, 2010, p. 101).

Se, de um lado, o anúncio aborda um Discurso de uma comunidade de prática feminista, que tenta estimular a diversidade e aceitação de que a mulher não deve ser objetificada, de outro lado, temos um Discurso patriarcal, machista, manifestado por comentários feitos à propaganda, que não aceita e nega esse novo comportamento. Os discursos dos consumidores da Skol, que falam em boicotar a marca, são, portanto, estimulados por um Discurso que se opõe à luta feminina. Gênero, nesses termos, não é mais um substantivo, ou um conjunto de atributos flutuantes, é um efeito substantivo "performativamente produzido e imposto pelas práticas reguladoras da coerência do gênero" (BUTLER, 2016, p. 56).

Se a leitura de Carolina se deteve ao aspecto verbal, a leitura de Marie e a de Frida (influenciada por Marie) foi mais próxima do que estaria para uma leitura 
orientada pela pedagogia dos multiletramentos. Marie vê o aspecto da inclusão sendo amarrado de maneira que inclua a mulher na prática de beber cerveja, e que isso é para agradar ao público feminino, mas ressalta que o argumento ainda escorrega ao optar pela utilização dos cartazes antigos que expõem os corpos femininos no modo visual (Excerto 2, linhas 13-18).

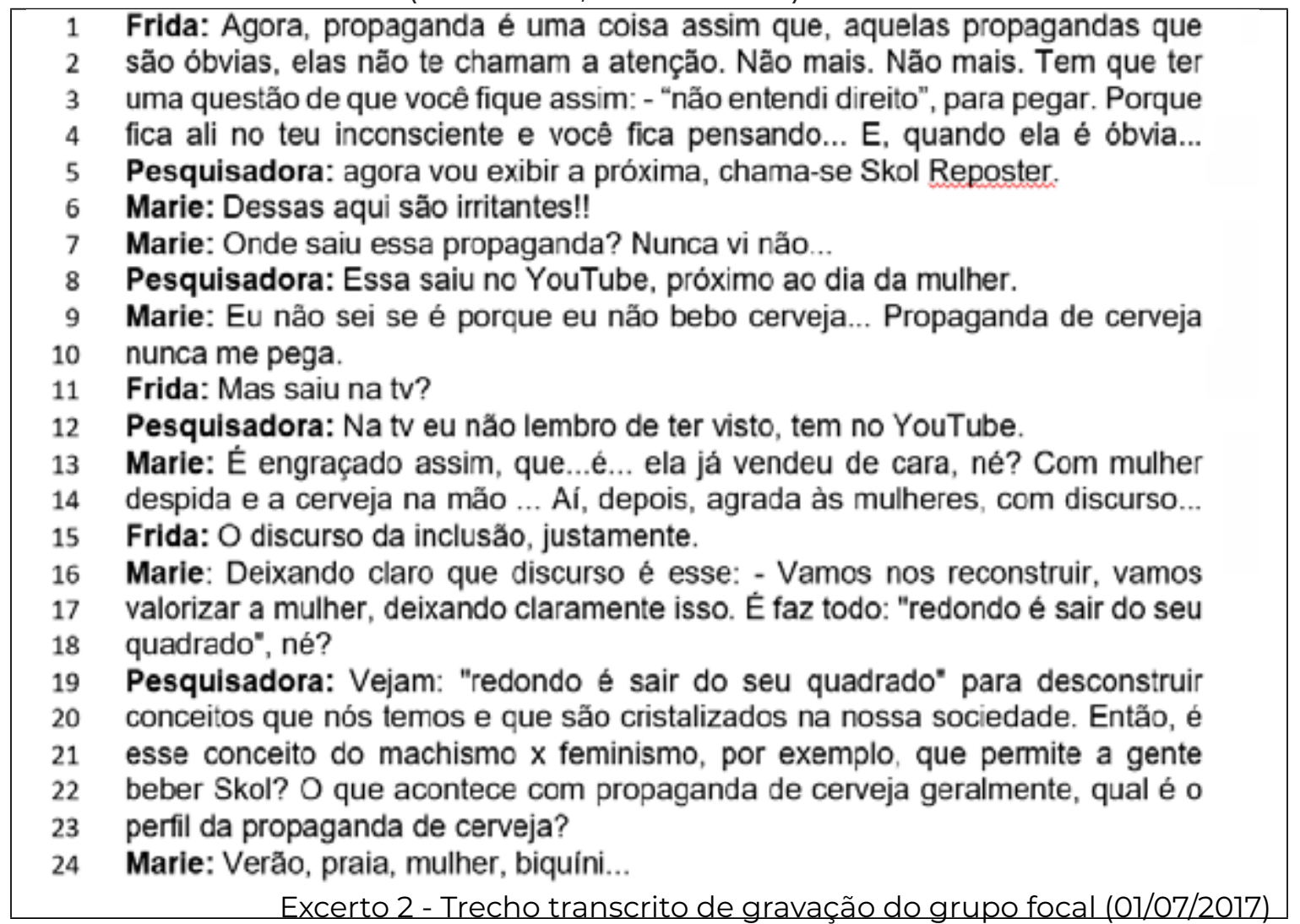

Verifico que a leitura de Marie, mesmo não tendo influências, ainda, de uma metalinguagem como da GDV, por exemplo, alinha-se ao recurso da metafunção ideacional, pois Marie consegue identificar na narrativa, enquanto participante interativa, que as participantes representadas, no início do anúncio, ainda aparecem em uma condição subjugada, influenciada por um Discurso sexista.

Nicholson (1990), na introdução do livro Feminism/ Post modernism trata da discussão do corpo como um espaço. Para a autora, os corpos humanos não podem ser entendidos como infinitamente móveis e flexíveis, pois a compreensão humana possui limites necessários. Utilizando-se de uma fala de Bordo, cita: "a própria realidade pode ser implacavelmente plural e heterogênea, mas a compressão e o interesse humanos não podem ser" (BORDO, s.d, s.p citado por NICHOLSON, 1990, p. 9, tradução minha5). A autora ainda adverte que qualquer

5 "reality itself may be relentlessly plural and heterogeneous, but human understanding and interest cannot be". 
celebração de espaço é problemática, já que representa uma situação de contestação e negociação. Mas, para Nicholson (1990), é "na diferença e no como descrevemos as diferenças que fazem a diferença" que estamos atuando politicamente. (NICHOLSON, 1990, p. 9).

Essa afirmação de Nicholson (1990) de que as diferenças que fazem a diferença são em si, um ato político, pode ser verificada quando, nas linhas 10 e 11 (Excerto 3), as participantes dizem "Se o interesse fosse real...", "de fato, ne?". E reiteradas nas linhas 12 e 13, quando Marie diz: "Eu não entendo isso, porque, caramba!! Cerveja não é um produto que só homem consome... Batem tanto nessa imagem da mulher, e...":

Vejamos agora o Excerto (3):

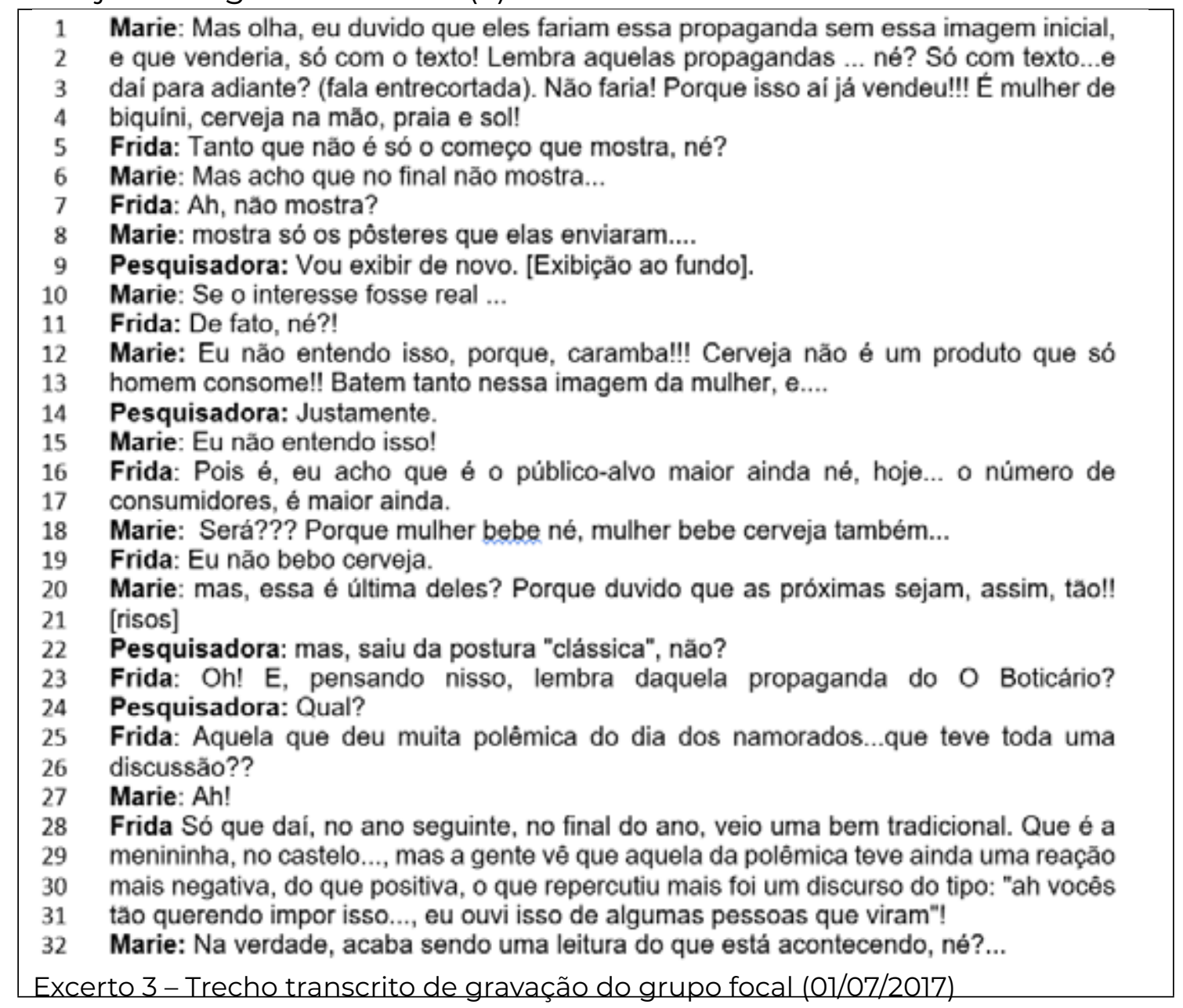

As participantes reclamam da forma como o roteiro foi apresentado, principalmente quando se trata da exposição do conflito (BARRETO, T., 2004), nos primeiros minutos do filme, o que pode ser observado na figura (1), apresentada anteriormente. Assim, o roteiro apresenta-se pelo efeito de um ato discursivo 
que reifica a necessidade de significar as identidades de gênero de forma binária. Como apontado por Butler (2016, p. 249),

compreender a identidade como uma prática, e uma prática significante, é compreender sujeitos culturalmente inteligíveis como efeitos resultantes de um discurso amarrado por regras, e que se insere nos atos disseminados e corriqueiros da vida linguística. (BUTLER, 2016, p. 249)

Essa divisão se revela durante todo o audiovisual e, pela metafunção representacional, é possível verificar que os pontos de vista podem ser expressos pelo contato, marcando a orientação do olhar das participantes representadas (KRESS; VAN LEEUWEN, 2006). Até a apresentação dos pôsteres recriados, quando ocorre o clímax do filme publicitário, o olhar das participantes representadas é de oferta, porque elas não olham para o participante interativo - figura (3). 0 contato só é feito depois que os pôsteres recriados são apresentados ao leitor, pelo olhar direto das participantes representadas - figura (4).

\section{Figura 3 - o contato entre participantes representada e participante interativo}

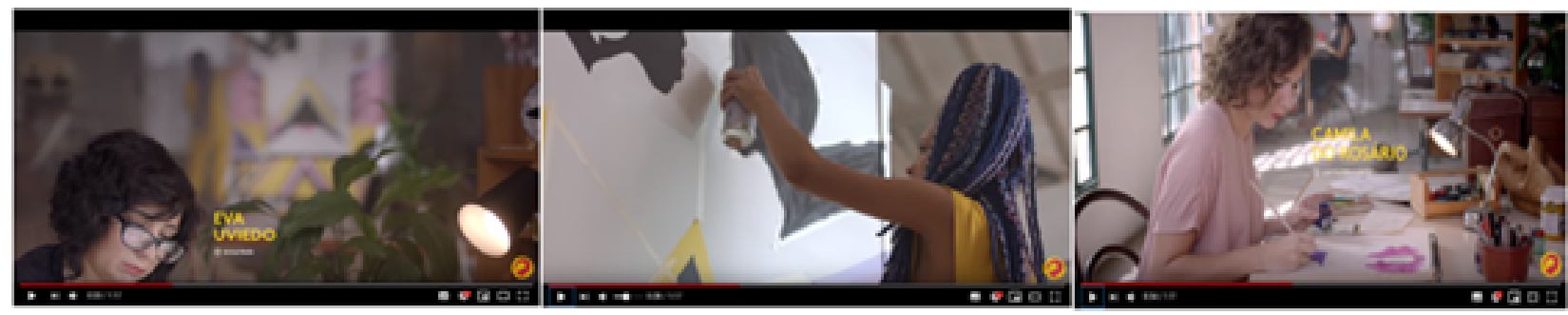

1

2

3

Fonte: https://www.youtube.com/watch?v=tuaP-7P4w2w

Figura 4 - o contato depois da apresentação dos pôsteres

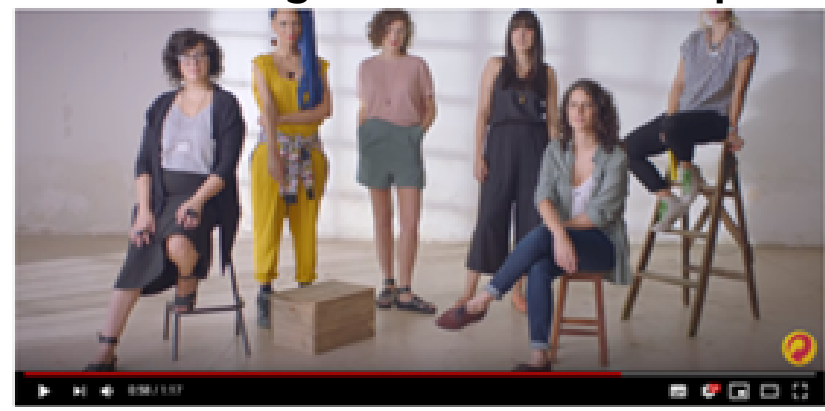

1

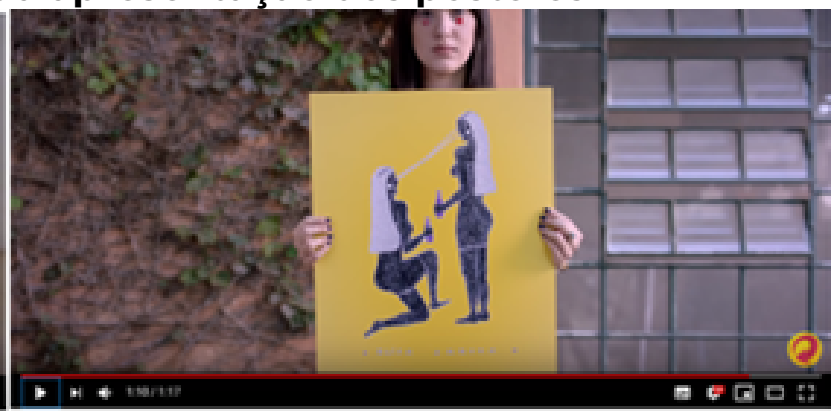

2

Fonte: https://www.youtube.com/watch?v=tuaP-7P4w2w

Os frames das figuras (3 e 4) revelam outro aspecto, o do distanciamento social entre as PR (participantes representadas) e o PI (leitor). Os enquadramentos são marcados pelas escolhas dos planos que, no anúncio, desde a apresentação do conflito - a refacção do pôster- até que a resolução seja proposta - o pôs- 
ter refeito - a maioria dos enquadres é feita em plano fechado (close shot), já que a imagem mostra a cabeça e os ombros das participantes - figura (3). Quando a resolução do conflito acontece, o enquadramento muda, apresentando-se em plano aberto (long shot), pois além do corpo, é possível ver o cenário - figura (4). Esses planos revelam que há momentos no anúncio da Skol em que as relações entre o espectador são mais distantes e, outros, que são de intimidade (cf. KRESS; VAN LEEUWEN, 2006, p. 118- 119).

\section{Considerações finais}

As atividades realizadas no curso e as análises dos anúncios no grupo focal evidenciaram a importância que tem o fortalecimento entre a prática e a teoria. Isto é, utilizar uma metalinguagem que contribua para a compreensão leitora do que seja uma leitura multimodal. Elas mostraram a necessidade de se investir no processo formativo bem como a possibilidade de discussão sobre temas relacionados às diferenças de gênero.

Pela análise desenvolvida no texto em tela, é perceptível que a imagem em movimento carrega recursos disponíveis e ferramentas que projetam e redesenham as identidades de gênero, diante de uma construção discursiva que leva a sociedade a adotar ideologias e filosofias de vida, já que os diferentes modos pelos quais o anúncio foi construído mostram as diferenças sociais que são significadas e reificadas por (D)iscursos e (d)iscursos sobre as identidades femininas.

\section{Referências}

BAUER, M. W.; GASKELL, G. Pesquisa qualitativa com texto, imagem e som: um manual prático. (p. A. Guareschi, trad.). Petrópolis: Vozes, 2008.

BUTLER, J. Problemas de gênero. Rio de Janeiro: Civilização Brasileira, 2016.

BARRETO, T. Vende-se em 30 Segundos: Manual Do Roteiro Para Filme Publicitário. São Paulo: Senac, 2004.

CAZDEN, C. et al. A Pedagogy of Multiliteracies: Designing Social Futures. Harvard Educational Review, v. 66, n. 1, p. 60-92, Spring 1996.Disponível em: http://newarcproject.pbworks.com/f/Pedagogy+of+Multiliteracies_New+London+Group.pdf. Acesso em: 02/12/2020

CAVALCANTI, M. C.; MAHER, T. M. Diferentes Diferenças: Desafios interculturais na sala de aula. 1. ed. Campinas: CEFIEL/MEC, 2009.

DALEY, E. Expandindo o conceito de letramento. Trab. linguist. apl. [online]. 2010, vol.49, n.2, pp.481-491. ISSN 2175-764X. <http://dx.doi.org/10.1590/S0103-18132010000200010>. 
DOMINGO, M., JEWITT, C., KRESS, G. Multimodal social semiotics: Writing in online contexts. In: K. Pahl and Rowsel (eds.). The Routledge Handbook of Contemporary Literary Studies. London: Routledge, 2014.

ECKERT; P; MCCONNELL-GINET, S. Comunidades de práticas: lugar onde co-habitam linguagem, gênero e poder. In: OSTERMANN, A. C.; FONTANA, B. Linguagem, sexo, sexualidade. São Paulo: Parábola Editorial, 2010. [original de 1992]

ERICKSON, F. Métodos cualitativos de investigación sobre La ensinanza. In:

WITTROCK, M. C. (Org.). La investigación de La enseñanza, Il: métodos cualitativos y de observación. Barcelona: Paidos, 1989. p. 195-301.

ESPINOSA. B. Tratado Teológico-Político. Trad. de Diogo Pires Aurélio. São Paulo: Martins Fontes: 2003.

GEE, J. P. Social Linguistics and Literacies: Ideology in Discourses. 3. ed. London, Routledge, 2008.

GUERRA, P. B. de C. Psicologia social dos estereótipos. Psico-USF (Impr.), Itatiba, v. 7, n. 2, p. 239-240, Dec. 2002. Available from <http://www.scielo.br/scielo.php?script=sci_arttext\&pid=S1413-82712002000200013\&lng=en\&nrm=iso>. access on 27 May 2019. http://dx.doi. org/10.1590/S1413-82712002000200013.

HALLIDAY, M. A. K. An Introduction to Functional Grammar. London: Edward Arno, 1994.

JEWITT, C.; OYAMA, R. Visual meaning: a social semiotic approach. In: VAN LEEUWEN, T.; JEWITT, C. (Eds). Handbook of visual analysis. London: SAGE PublicationsLtd, 2004.

KRESS, G; JEWITT, C. (Orgs.). Multimodal literacy. New York: Peter Lang Publishing, 2003.

KRESS, G.; VAN LEEUWEN, T. Reading images: The Grammar of Visual Design. London: New York: Routledge, 2006 [1996].

LANKSHEAR, C.; KNOBEL, M. Pesquisa pedagógica: do projeto à implementação. Porto Alegre: Artmed, 2008.

MAHER, T. M. A educação do entorno para a interculturalidade e o plurilinguismo. In: KLEIMAN, A. B.; CAVALCANTI, M. C. (orgs.). Linguística aplicada: suas faces e interfaces. Campinas, SP: Mercado de Letras, 2007.

MARTINS, J. S. Redação Publicitária Teoria e Prática. 3.ed. São Paulo: Editora Atlas, 2011.

NICHOLSON, L. Interpreting Gender. In: The Play of Reason: From the Modern to the Postmodern. Cornell University Press, 1999. p. 53-76.

NICHOLSON, L. Introdução. Feminism/Postmodernism. Linda. J. Nicholson (ed). New York: Routledge, 1990.

PINHEIRO, P. A. Sobre o manifesto "A Pedagogy of Multiliteracies: designing social futures" 20 anos depois. Trab. linguist. apl., Campinas, v. 55, n. 2, p. 525-530, ago. 2016. Disponível em <http://www.scielo.br/scielo.php?script=sci_arttext\&pid=S0103=18132016000200525-\&lng=pt\&nrmiso >. acessos em 27 maio 2019. http://dx.doi.org/10.1590/010318135166183471.

SILVA, T. T. da; HALL, S.; WOODWARD, K.. Identidade e diferença: A perspectiva dos Estudos 
Culturais. 15. ed. Petrópolis, Rj: Vozes, 2014.

WOODWARD, K. Identidade e diferença: uma introdução teórica e conceitual. In: Tomaz Tadeu da Silva (org.) Identidade e diferença: a perspectiva dos Estudos Culturais. 15. ed. Petrópolis, RJ: Vozes, 2014.

\section{Sobre a autora}

Roziane Keila Grando - Doutora em Linguística Aplicada (Universidade Estadual de Campinas-IEL/ UNICAMP). Professora substituta do curso de Letras da Universidade Estadual do Centro-Oeste (UNICENTRO) - Guarapuava - PR; E-mail: kekegrando@yahoo. com.br; Lattes: http://lattes.cnpq.br/8778811156995344. OrclD: https://orcid.org/O0000001-6259-8878. 